\title{
Azul de Toluidina contra o câncer: bom e barato
}

\author{
Toluidine Blue Against Cancer: Good and Cheap
}

Lejoy A., Arpita R., Krishna B., Venkatesh N. Methylene blue as a diagnostic aid in the early detection of potentially malignant and malignant lesions of Oral

Mucosa. Ethiop J Health Sci. 2016, 26(3):201-208.

BRuna Maria Rodrigues VILARDI*

TAISA MARIA RodRIgUes VILARDI*

O câncer é uma doença genética na qual ocorrem mutações celulares, a etiologia é multifatorial, herdada e adquirida. A partir de uma célula mutada ocorre replicação de células atípicas, originando uma neoplasia. Os hábitos nocivos são considerados a principal justificativa no aumento da incidência de neoplasias malignas. Para um prognóstico favorável, é necessária detecção precoce de lesões orais potencialmente malignas orais (POMD), de acordo com a Organização Mundial de Saúde, que são: a leucoplasia, a eritroplasia, a queilite actínica, e o líquen plano oral. Entretanto, qualquer lesão elencada pode não apresentar displasias celulares, sendo necessária a proservação.

O câncer de boca está entre as principais malignidades da população mundial. O tumor maligno de boca prevalente é o carcinoma espinocelular. Embora a maioria dos diagnósticos da doença seja feito tardia e clinicamente, havendo PMOD ou carcinoma, há alterações morfológicas na mucosa bucal incluindo alterações da superfície da lesão, perda de integridade tecidual, cor, tamanho, bordas, base, consistência à palpação e histórico de evolução. O exame complementar de eleição é a biópsia seguida pela análise histopatológica, sendo esse método de diagnóstico eficaz e seguro.

Diversas técnicas de diagnóstico vêm sendo desenvolvidas ou adaptadas da área médica para a odontológica, onde ênfase especial merece a técnica de rastreamento com o Azul de Toluidina (AT), preconizada por ser de fácil aplicação e baixo custo, com a finalidade de evidenciar áreas de degeneração tecidual. Essa técnica do AT foi primeiramente utilizada para detectar precocemente alterações na mucosa do aparelho reprodutor feminino e epitélio conjuntivo ocular, sendo também empregada há décadas na odontologia. O corante AT é cientificamente denominado de cloreto de tolônio, faz parte do grupo tiazina dos corantes metacromáticos. O composto químico frequentemente é formado por um duplo sal de cloreto de zinco do grupo amino dimetil, o cloreto amino-tolufenotiazínico. Esse tem como mecanismo de ação a afinidade do AT por ácidos nucleicos celulares que estão presentes em maior quantidade nas células alteradas. Dessa forma, essas células absorvem maior quantidade de AT e geram manchas azul-escuras intensas, o que é interpretado como regiões com maior probabilidade de possuírem displasia epitelial.

\footnotetext{
' Professoras da Universidade Metodista de Piracicaba

"Faculdade de Odontologia de Lins
} 
As áreas demarcadas servem de orientação para o local de eleição para a realização de uma biópsia.

Embora a técnica seja considerada de alta confiabilidade, tem sua limitação: o AT de uso tópico atinge de três a quatro camadas de células. Portanto, em lesões malignas iniciais, onde as camadas superfícies do epitélio de revestimento estejam livres de alterações, não há impregnação do corante. Regiões de ulceração em processo de regenerações epiteliais promovem alta absorção do AT, portanto, nos queratinócitos que estão em mitose promovem um resultado falso positivo, ou seja, não há células displásicas no tecido. Falsos positivos podem ocorrer em tecidos com inflamação instalada. Outra falha da aplicação do AT se dá em displasias severas recobertas por queratina ou carcinomas recobertos por mucosa saudável, impossibilitando a penetração do AT. Mediante as intercorrências da técnica, reforça-se o exame clínico de excelência para orientar a escolha de exames complementares.

A manobra estomatológica de AT consiste em secar e isolar da contaminação salivar a região a ser examinada, apreendendo o local com os dedos e gaze. Por meio de uma haste flexível com algodão, realiza-se a aplicação de ácido acético 1\% (solução ácida) com finalidade de limpeza da superfície da lesão e remoção da barreira de glicoproteínas celulares e promover uma leve desidratação da mucosa; aguardar 1 minuto; em seguida com o outro lado da haste de algodão aplica-se o corante tecidual AT; aguardar 1 minuto; realizar novamente a limpeza dos excessos com ácido acético $1 \%$ e fazer uma lavagem com água abundante. O resultado tem finalidade de evidenciar áreas intensamente coradas compatíveis com regiões de degeneração tecidual. Existe também, com a mesma finalidade diagnóstica, uma técnica em que o AT passa por aplicação de quimioluminiscência.

Lejoy et al. (2016) exploraram bem o uso dessa técnica e sua efetividade no diagnóstico precoce de lesões potencialmente malignas.

A técnica de AT é considerada um método auxiliar de alta sensibilidade, agregando qualidade ao exame físico na prevenção do câncer bucal, entretanto, é pouco divulgada e esclarecida por cirurgiõesdentistas. Interessantemente, pode ser indicada para a sua utilização por acadêmicos e profissionais com pouca experiência clínica, por não ter caráter invasivo e ser de fácil uso e interpretação clínica. 